\title{
Analisis Pengaruh Positioning Daya Tarik Wisata Terhadap Keputusan Wisatawan Untuk Berkunjung Di Objek Wisata Kebun Raya Unmul Samarinda
}

\author{
A. Rinto Dwiatmojo ${ }^{1 *}$, dan Isransyah Nur $^{2}$ \\ ${ }^{1}$ rinto_dwiatmojo@polnes.ac.id; ${ }^{2}$ isransyah14@ymail.com \\ ${ }_{1,2}$ Jurusan Pariwisata Politeknik Negeri Samarinda, Kota Samarinda, 75136, Indonesia \\ ${ }^{1,2} \mathrm{Jl}$. DR. Ciptomangunkusumo, Kampus Gunung Lipan, Samarinda, Kalimantan Timur, Indonesia $75131 \mid$ Hot line: \\ PABX (+62541) 260588, FAX: (+62541) 260355 \\ * corresponding author
}

ARTICLE INFO (8 pt)

Article history:

Received

Revised

Accepted

Keywords: Positioning, Tourists Attraction, Tourist

Kata kunci: Positioning, Obyek Wisata, Wisatawan

\section{ABSTRACT (10PT)}

This study aims to determine whether the positioning variable has a partial and simultaneous influence on the decision of tourists to visit the Samarinda Unmul Botanical Garden? Which is the most dominant influence on the decision of tourists visiting the Botanical Gardens Unmul Samarinda? This study uses Multiple Regression analysis to analyze research results. Ha is accepted that there is an influence between the experimental concept on the decision of tourists to visit. This is evidenced by the value of tcount $>$ t table (3.049> 1.661), the significance is less than 0.05 (0.003 <0.05), and the regression coefficient has a positive value of 0.264 . The results of this study, Ha is accepted there is an influence between price concept of tourists' decision to visit. This is evidenced by $t$ arithmetic $>t$ table $(2.301>1.661)$, the significance is less than 0.05 $(0.024<0.05)$, and the regression coefficient has a positive value of 0.152. (Ha is accepted, Ho is rejected), Ha is accepted, there is an influence between the attribute product concept on the decision of tourists to visit. This is evidenced by $t$ arithmetic $>t$ table (4.366> 1.661), the significance is less than 0.05 (0.000 <0.05), and the regression coefficient has a positive value of 0.355 . (Ha is accepted, $\mathrm{Ho}$ is rejected), $\mathrm{Ha}$ is accepted, there is an influence between positioning which consists of experimental concept, price concept, and product attribute concept on the decision of tourists to visit. This is evidenced by the calculated $F$ value $>F$ table (29.882> 2.70) with a significance value of less than 0.05 (0,000 <0.05). (Ha accepted, Ho rejected), the product concept attribute variable was the dominant factor influencing tourists' decision to visit the Samarinda Unmul Botanical Garden with a coefficient of 0.398, then the second rank was occupied by the experimental concept variable with a coefficient of 0.249, and the last ranking was occupied by the variable price concept with a coefficient of 0.218 .

\section{ABSTRAK}

Penelitian ini bertujuan untuk mengetahui Apakah variable positioning terdapat pengaruh secara parsial dan simultan terhadap keputusan wisatawan untuk berkunjung Di Kebun Raya Unmul Samarinda ? Manakah yang paling dominan berpengaruh terhadap Keputusan wisatawan berkunjung Di Kebun Raya Unmul Samarinda ? Penelitian ini mengunakan analisis Regresi Berganda untuk menagalisis hasil penelitian. Ha diterima ada pengaruh antara experimental concept terhadap keputusan wisatawan untuk berkunjung. Hal ini dibuktikan dengan nilai thitung $\mathrm{t}_{\text {hitung }}>\mathrm{t}$ tabel 
$(3,049>1,661)$, signifikansi lebih kecil dari $0,05(0,003<0,05)$, dan koefisien regresi mempunyai nilai positif sebesar 0,264 Hasil penelitian ini, Ha diterima ada pengaruh antara price concept terhadap keputusan wisatawan untuk berkunjung. Hal ini dibuktikan dengan $\mathrm{t}$ hitung $>\mathrm{t}$ tabel $(2,301>1,661)$, signifikansi lebih kecil dari $0,05(0,024<0,05)$, dan koefisien regresi mempunyai nilai positif sebesar 0,152. ( Ha diterima,Ho ditolak), Ha diterima ada pengaruh antara atribute produk concept terhadap keputusan wisatawan untuk berkunjung. Hal ini dibuktikan dengan $\mathrm{t}$ hitung $>\mathrm{t}$ tabel $(4,366>1,661)$, signifikansi lebih kecil dari $0,05(0,000<0,05)$, dan koefisien regresi mempunyai nilai positif sebesar 0,355. (Ha diterima,Ho ditolak), Ha diterima ada pengaruh antara positioning yang terdiri dari experimental concept, price concept, dan atribute produk concept terhadap keputusan wisatawan untuk berkunjung. Hal ini dibuktikan dengan nilai $\mathrm{F}$ hitung > F tabel $(29,882>2,70)$ dengan nilai signifikansi lebih kecil dari 0,05 $(0,000<0,05)$. ( $\mathrm{Ha}$ diterima,Ho ditolak), Variabel atribute product concept merupakan faktor dominan yang mempengaruhi keputusan wisatawan untuk berkunjung di Kawasan Kebun Raya Unmul Samarinda dengan koefisien sebesar 0,398, kemudian peringkat kedua diduduki variabel experimental concept dengan koefisien sebesar 0,249, dan peringkat terakhir diduduki variabel price concept dengan koefisien sebesar 0,218 .

Copyright ( 2019 Politeknik Negeri Samarinda. All rights reserved.

\section{Pendahuluan}

Untuk menempatkan citra baik pada Kebun RayaSamarinda tersebut perlu positioning yang baik sehingga dapat memiliki kesan baik di benak wisatawan dan mampu mendorong keinginan wisatawan untuk berkunjung ke daya tarik wisata ini. Keputusan wisatawan berkunjung biasanya dipengaruhi oleh beberapa hal penilaian oleh mereka mulai dari fasilitas yang disediakan, kondisi sekitar tempat wisata, akses jalan menujuke tempat wisata juga tidak luput dari perhatian wisatawan. Dalam memasarkan produk Kebun Raya Samarinda, Dinas Pariwisata, Ekonomi Kreatif dan Kominfo Kota Samarinda tidak hanya mempromosikan produk wisatanya saja.

Sebagai upaya memperkenalkan produk wisatanya dalam hal ini Dinas Pariwisata, Ekonomi Kreatif dan Kominfo Kota Samarinda memposisikan daya tarik wisata Kebun Raya Unmul Samarinda pada Experiental Concept, Price dan Atribute Product guna mengetahui apa yang membuat wisatawan mau datang berkunjung ke daya tarik wisata tersebut. Berdasarkan latar belakang masalah yang dijelaskan diatas, maka penulis merumuskan masalah penelitian sebagai berikut, Apakah variable positioning terdapat pengaruh secara parsial dan simultan terhadap keputusan wisatawan untuk berkunjung Di Kebun Raya Unmul Samarinda, Manakah yang paling dominan berpengaruh terhadap Keputusan wisatawan berkunjung Di Kebun Raya Unmul Samarinda?

Suatu konsep yang digambarkan dalam definisi konsep tertentu saja tidak akan dapat diobservasi atau diukur gejalanya dilapangan. Untuk dapat diukur, maka suatu konsep harus didefinisikan secara operasional. Dalam hal ini operasional sebagai berikut :

\section{Tinjauan Pustaka}

Penelitian ini menggunakan teori-teori dasar maupun terapan disertai dengan konsep-konsep definitif yang jelas sebagai alat analisis untuk memperoleh hasil penelitian yang objektif dan akuntabel dalam proses penggalian data.

\section{Definisi operasional X1 Experimental concept}

Experimental concept (X1) adalah menonjolkan experimental needs (keramahan dan kenyamanan). Pengelola objek Kebun Raya Unmul Samarinda berupaya selalu memberikan kenyamanan pada wisatawan yang sedang berkunjung dan juga ditunjang 
dengan keramahan pelayanan. yang diberikan. Experimental concept (X1) dilihat dari :

1) Keramahan,diukur dengan pelayanan petugas tempat wisata selalu diutamakan demi kepuasan wisatawan saat berkunjung sehingga.

2) Kenyamanan, diukur dengan memperhatikan keadaan sekitar lokasi wisata oleh pengelola lokasi wisata merupakan hal penting mengingat lokasi wisata yang menfaatkan keadaan alam sebagai daya tarik utama.

2. Definisi operasional X2 Price Quality Concept

Price Quality concept (X2) adalah menggunakan paling rendah sampai paling tinggi (harga rendah dan harga tinggi). Tinggi rendahnya harga pada obejek wisata Kebun Raya Unmul Samarinda terjadi pada hari-hari tertentu dan jumlah kunjungan wisatawan akan meningkat. Price Quality concept (X2) dilihat dari :

1) Harga rendah, diukur dengan adanya potongan harga untuk wisatawan rombongan yang sudah ditetapkan jumlahnya dan potongan harga tidak berlaku pada hari libur dan hari minggu.

2) Harga tinggi, diukur dengan adanya kenaikan harga pada saat sedang diselenggarakannya acara yang melibatkan objek wisata Kebun Raya Unmul Samarinda.

\section{Definisi operasional X3Atribute Positioning Produk Concept}

Atribute Positioning Produk Concept (X3) adalah menonjolkan satu atau beberapa atribut feature-customen benefits yang dihubungkan dengan merek, manfaat bagi pelanggan (derajat kepentingan dan keunikan) keunikan yang ada pada objek wisata Kebun Raya Unmul Samarinda terletak pada lahan yang sangat luas untuk berrekreaksi. Atribute Positioning Produk Concept (X3) dilihat dari :

1) Derajat Kepentingan, diukur dengan melakukan konservasi atau penelitian di Kawasan Kebun Raya Unmul Samarinda
2) Keunikan,diukur dengan adanya daya tarik wisata terdapat pada daya tarik wisata alam dan juga merupakan salah satu objek wisata yang popular di Samarinda.

\section{Definisi operasional Y Keputusan Berkunjung}

Keputusan wisatawan berkunjung (Y) adalah keinginan wisatawan untuk berkunjung ke tempat yang diinginkan demi memenuhi kepuasan yang mereka inginkan dengan merasakan hal baru yang belum pernah meraka rasakan di daya tarik wisata Kebun Raya Unmul Samarinda. Keputusan berkunjung dilihat dari :

1) Kunjungan berulang, diukur dengan seorang wisatawan kembali berkunjung kesuatu daya tarik.

2) Rekomendasi atau informasi teman, diukur dengan seorang wisatawan akan menyampaikan informasi tentang wisata yang telah dikunjungi pada temannya.

\section{Metodologi Penelitian}

\section{A. Teknik Pengumpulan Data}

Dalam penelitian ini, peneliti memilih beberapa metode pengumpulan data untuk mendapatkan data yang akurat dan kredibel, sehingga penelitian ini dapat dipertanggungjawabkan sebagai karya tulis ilmiah, yaitu:

\section{Populasi}

Menurut Sugiyono (2013:148) populasi adalah wilayah generalisasi yang terdiri atas subjek yang mempunyai kuantitas dan karakteristik tertentu yang ditetapkan oleh peneliti untuk dipelajari dan kemudian ditarik kesimpulannya. Populasi yang diambil adalah pengunjung daya tarik wisata alam Kebun Raya Unmul Samarinda. Jumlah populasi yang ada di Kebun Raya Unmul Samarinda selama bulan februari sampai April ialah 12.541 orang.

\section{Ukuran Sampel}

Cuplikan sampel (unit analisis) setidaknya diambil berdasarkan ukuran sampel minimal dari jumlah anggota populasi yang sangat 
besar (jumlahnya tidak diketahui). Ukuran sampel untuk sebuah penelitian antara 30500 orang, untuk memenuhi pertimbangan metodologis yang paling rasional dalam penelitian ini mengambil sampel sebanyak 100 orang yang mewakili populasi.

$$
\mathrm{n}=\frac{\mathrm{N}}{1+\mathrm{N}(\mathrm{e})^{2}}
$$

Dimana :

$\mathrm{n}=$ Ukuran sampel yang dibutuhkan

$\mathrm{N}=$ Ukuran populasi

$\mathrm{E}=$ Ukuran tingkat kesalahan sebesar 10\% jadi, besar nya sampel yang diteliti adalah

$$
\begin{aligned}
\mathrm{n} & =\frac{12.541}{1+12.541(0,1)^{2}} \\
& =\frac{12.541}{125,42} \\
& =99,9 \\
& =100
\end{aligned}
$$

\section{B. Teknik Analisis Data}

Teknik analisis data yang pertama kali dilakukan adalah pengujian instrument. Pengujian instrumen bertujuan untuk memperoleh informasi sudah atau belum terpenuhinya persyaratan instrumen. Dikatakan memenuhi syarat sebagai alat untuk mengumpulkan data jika instrumen tersebut valid dan reliable. Uji coba instrumen dalam penelitian ini dilakukan pada 30 orang atau pengunjung daya tarik wisata alam Kebun Raya Unmul Samarinda, yang tidak termasuk dalam sampel penelitian. Untuk lebih jelasnya di bawah ini akan di uraikan uji validitas dan uji reliabi litas instrumen.

\section{Analisis Regresi Liniear Berganda}

Analisis regresi adalah suatu analisis yang mengukur pengaruh antar variabel bebas terhadap variabel terikat. Analisis regresi ini termasuk dalam salah satu analisis kuantitatif. Analisis kuantitatif adalah analisis yang bersifat hitungan statistik dengan menerapkan rumus-rumus untuk menguji kebenaran data teori dan hipotesis. Pertimbangan penggunaan analisis kuantitatif adalah kesesuaian model konsepsional, karakteristik pengukuran dan jenis data penelitian ini, oleh karena itu metode analisis yang paling cocok dalam penelitian adalah analisis regresi linier berganda (multiple regression), rumusannya sebagai berikut:

$\mathrm{Y}=\mathrm{a}+\mathrm{b} 1 \mathrm{X} 1+\mathrm{b} 2 \mathrm{X} 2+\mathrm{b} 3 \mathrm{X} 3+€$

Dimana :

$\mathrm{Y}=$ Keputusan Bekunjung

a $=$ Konstanta

b1,b2,b3 = Koefisien regresi

$\mathrm{X} 1=$ Experimental Concept

$\mathrm{X} 2=$ Price Concept

$\mathrm{X} 3=$ Atribute Product Concept

$€ \quad=$ Erorr

\section{Hasil dan Diskusi}

\section{Analisis Regresi Linier Berganda}

Analisis data yang dilakukan untuk pengujian hipotesis dalam penelitian ini adalah analisis regresi berganda. Di bawah ini akan dibahas hasil analisis regresi berganda yang dilakukan dengan menggunakan program SPSS 16.00 for windows.diperoleh hasil seperti yang tertera di bawah ini :

Hasil Analisis Regresi Linier Berganda

Coefficients $^{\mathrm{a}}$

\begin{tabular}{|c|c|c|c|c|c|}
\hline Model & \multicolumn{2}{|l|}{$\begin{array}{l}\text { Unstandardized } \\
\text { Coefficients }\end{array}$} & $\begin{array}{c}\text { Standardized } \\
\text { Coefficients }\end{array}$ & \multirow{2}{*}{ T } & \multirow{2}{*}{} \\
\cline { 2 - 4 } & B & Std. Error & Beta & & \\
\hline (Constant) &, 706 &, 276 & & 2,556 &, 012 \\
X1 &, 264 &, 087 &, 249 & 3,049 &, 003 \\
X2 &, 152 &, 066 &, 218 & 2,301 &, 024 \\
X3 &, 355 &, 081 &, 398 & 4,366 &, 000 \\
\hline
\end{tabular}

Sumber: Data Diolah 2015

Dari hasil analisis regresi dapat diketahui persamaan regresi berganda sebagai berikut:

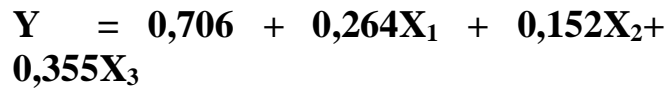

A. Koefisien regresi pada variable Experimental Concept $\left(\mathrm{X}_{1}\right)$ sebesar 0,264 menyatakan bahwa "Ada pengaruh antara experimental concept 
terhadap keputusan wisatawan untuk berkunjung" terbukti. Besarnya nilai koefisien sebesar 0,264; hal ini menunjukkan bahwa variabel experimental concept menduduki peringkat kedua yang mempengaruhi keputusan wisatawan untuk berkunjung.

B. Koefisien regresi pada variabel Price Concept $\left(X_{2}\right)$ sebesar 0,152 menyatakan bahwa "Ada pengaruh antara atribute produk concept terhadap keputusan wisatawan untuk berkunjung" terbukti.Besarnya nilai koefisien sebesar 0,152 ; hal ini menunjukkan bahwa variabel price concept menduduki peringkat ketiga yang mempengaruhi keputusan wisatawan untuk berkunjung.

C. Koefisien regresi pada variabel Atribute Prodoct Concept $\left(\mathrm{X}_{3}\right)$ sebesar 0,355 menyatakan bahwa "Ada pengaruh antara atribute produk concept terhadap keputusan wisatawan untuk berkunjung" terbukti.Besarnya nilai koefisien sebesar 0,355; hal ini menunjukkan bahwa variabel atribute positioning produk concept menduduki peringkat pertama atau merupakan faktor dominan yang mempengaruhi keputusan wisatawan untuk berkunjung.

Penelitian ini bertujuan untukmengetahui pengaruh antara positioning yang terdiri dari experimental concept, price quality concept, dan atribute positioning produk concept terhadap keputusan wisatawan untuk berkunjung di Kawasan Kebun Raya Unmul Samarinda.Pembahasan masing-masing variabel disajikan sebagai berikut.

1. Pengaruh antara Experimental Concept terhadap Keputusan Wisatawan Untuk Berkunjung di Kawasan Kebun Raya Unmul Samarinda

Hasil penelitian menunjukkan bahwa ada pengaruh antara experimental concept terhadap keputusan wisatawan untuk berkunjung.Ada beberapa metode pendekatan yang dapat digunakan untuk melakukan positioning salah satunya melalui experimental concept. Experimental concept, posisi produk dirancang lebih menonjolkan pada bentuk pemenuhan kebutuhan pengalaman mencoba produk (experimental needs) misalnya layanan yang ramah, fasilitas yang lengkap dan terawat, tempat yang nyaman dan sebagainya.

Biasanya pengunjung akan berkunjung ke suatu tempat wisata dapat dipengaruhi oleh beberapa perhitungan-perhitungan tertentu mulai dari lokasi tempat tujuan wisata yang akan dituju dapat dijangkau dan lokasinya strategis, di sisi lain ada juga pengunjung yang menginginkan tempat wisata yang memiliki tantangan tersendiri untuk dicoba agar memberikan pengalaman di daerah daya tarik wisata, selain itu perhitungan murah dan mahalnya harga atau biaya untuk berlibur juga menjadi perhitungan yang sangat sensitive. Fasilitas yang disediakan oleh tempat wisata juga menjadi perhatian yang sangat penting bagi pengunjung karena fasilitas wisata sangat diperlukan oleh sebagian besar pengunjung, serta keamanan dan kenyaman maupun kebersihan juga tidak luput dari perhatiaan pengunjung, agar pengunjung merasa senang saat berkunjung ke kawasan Kebun Raya Unmul Samarinda

2. Pengaruh antara Price Concept terhadap Keputusan Wisatawan UntukBerkunjung di Kawasan Kebun Raya Unmul Samarinda

Hasil penelitian menunjukkan bahwa ada pengaruh, pengaruh antara price concept terhadap keputusan wisatawan untuk berkunjung.Faktor kedua yang berpengaruh terhadap keputusan wisatawan berkunjung adalah price concept. Harga adalah segala bentuk biaya moneter yang dikorbankan oleh konsumen untuk memperoleh, memiliki, memanfaatkan sejumlah kombinasi dari barang beserta pelyanan dari suatu produk.

Harga sebagai sejumlah uang yang harus dibayar untuk mendapatkan untuk mengunakan suatu produk. Dalam keputusan berkunjung, harga dapat menjadi faktor yang mempengaruhi keputusan berkunjung. Untuk mempengaruhi keputusan konsumen dalam berkunjung, Dalam rentang harga tertentu untuk suatu produk, konsumen mungkin mempunyai ekspektasi bahwa harga yang lebih mahal mencerminkan 
kualitas yang lebih baik. Oleh sebab itu, stimulasi harga dapat mempengaruhi konsumen secara berbeda-beda dalam pembuatan keputusan berkunjung terhadap suatu produk. Pada saat yang sama, penetapan dan persaingan harga menjadi salah satu hal yang sangat sering dihadapi oleh para eksekutif pemasaran.

Price quality concept merupakan posisi produk yang dirancang dengan menggunakan harga vs kualitas yang paling rendah sampai paling tinggi (harga rendah vs kualitas tinggi dan seterusnya). Adanya suatu produk wisata akan lebih lengkap jika diberikan harga karena dengan harga dapat dijadikan alat ukur untuk wisatawan dalam menilai kualitas sebuah paket wisata.

3. Pengaruh antara Atribute Positioning Product Concept terhadap Keputusan Wisatawan Untuk Berkunjung di Kawasan Kebun Raya Unmul Samarinda

Hasil penelitian menunjukkan bahwa ada pengaruh antara atribute product concept terhadap keputusan wisatawan untuk berkunjung. Faktor ketiga yang berpengaruh terhadap keputusan wisatawan berkunjung adalah atribute produk concept. Atribute product concept, menonjolkan satu atau beberapa atribut yang dihubungkan dengan merek, manfaat bagi pelanggan. Pada dasarnya yang biasa dimaksud dengan produk adalah sesuatu yang diciptakan melalui suatu proses terlebih dahulu kemudian hasil yang diciptakan dari proses tersebut dapat dinikmati demi memenuhi keinginan dan kebutuhan setiap individu.

Keputusan pengunjung akan suatu produk dapat memberikan kontribusi yang sangat menguntungkan bagi perusahaanperusahaan yang ada. Hal inilah yang harus dipertahankan oleh setiap perusahaan yang ingin tetap maju. Maka dari itu, perusahaan-perusahaan terutama perusahaan pariwisata sangat ketat dalam persaingan.Pemenuhan kebutuhan pengunjung ini tidak berarti hanya dalam bentuk penyediaan produk yang dibutuhkan saja, melainkan juga dengan melakukan kegiatan penyediaan kebutuhan-kebutuhan pengunjung lainnya dengan melakukan aktivitas-aktivitas pemasaran lainnya, yaitu aktivitas untuk mengkombinasikan bauran pemasaran. Dimana semua perusahaan harus melakukan aktivitas-aktivitas pemasaran, karena dengan cara inilah perusahaan akan mengetahui seberapa jauh produk yang ditawarkan dapat diterima oleh masyarakat atau pengunjung. Proses awal dalam pengambilan keputusan terhadap suatu produk adalah dengan melihat, sehingga akan menimbulkan kesan pada pengunjung terhadap produk tersebut.

Suatu produk yang ditawarkan ke pengunjung oleh perusahaan akan bertahan di pasaran jika atribut dari produk tersebut diterima oleh pengunjung, atribut produk adalah suatu komponen yang merupakan sifat-sifat produk yang menjamin agar produk tersebut dapat memenuhi kebutuhan dan keinginan yang diharapkan oleh pembeli, manfaat dari sebuah produk ini dikomunikasikan oleh atribut produk yang meliputi dari merek, kemasan, label, layanan pelengkap, jaminan (garansi), atribut produk diberikan kepada pengunjung bertujuan untuk tersebut dapat memenuhi kebutuhan dan keinginan yang diterapkan oleh pembeli.menarik pembeli dan jika atribut ini diterima maka pengunjung diharapkan akan merasa puas terhadap produk tersebut yang akhirnya menghantarkan pengunjung menjadi loyal terhadap produk tersebut.

4. Pengaruh Antara Positioning yang terdiri dari Experimental Concept, Price Concept, dan Atribute Produk Concept terhadap Keputusan Wisatawan Untuk Berkunjung di Kawasan Kebun Raya Unmul Samarinda.

Hasil penelitian menunjukkan bahwa ada pengaruh antara positioning yang terdiri dari experimental concept, price concept, dan atribute produk concept terhadap keputusan wisatawan untuk berkunjung.Strategi positioning ini digunakan pada berbagai sektor perusahaan, salah satunya adalah sektor pariwisata. Pariwisata merupakan sebuah industri jasa yang sedang berkembang dan merupakan salah satu industri terbesar saat ini yang berperan dalam meningkatkan pendapatan suatu 
negara. Dalam suatu pariwisata mempunyai Kumpulan macam-macam perusahaan, yang dimaksudkan antara lain travel agent, tourist transportation, hotel dan akomodasi lainya. Catering, bar dan restaurant, tour operator dan lain sebagainya. Semua perusahaan ini saling melengkapi sehingga merupakan industri sendiri yang hasilnya dibeli oleh wisatawan dalam bentuk paket wisata.

Daya tarik wisata merupakan komponen penting dalam pariwisata.karena daya tarik wisata merupakan tujuan wisatawan untuk datang berkunjung. Daya tarik wisata alam adalah objek wisata yang daya tariknya bersumber pada keindahan alam dan tata lingkungannya, baik dalam keadaan alami maupun setelah ada budidaya manusia.Wisata alam adalah bentuk kegiatan yang memanfaatkan potensi sumber daya alam dan tata lingkungannya. Kegiatan wisata alam dimaksud adalah kegiatan rekreasi dan pariwisata, penelitian, kebudayaan, dan cinta alam yang dilakukan di dalam objek wisata alam.

Kunci keberhasilan positioning terletak pada kemampuan pengelola objek wisata dalam menciptakan persepsi yang diinginkan pelanggan. Dalam era globalisasi seperti sekarang ini persaingan sudah sangat kompetitif, sehingga positioning menjadi sangat penting karena produk atau perusahaan tempat wisata yang baru tidak dapat bersaing langsung dengan tempat wisata yang sudah memiliki posisi yang kuat, mereka memiliki tempat tertinggi dan posisi teratas dalam pikiran pelanggan maupun calon pelanggan. Dalam situasi seperti ini, maka positioning dapat berperan memberi jalan untuk dapat bersaing disekelilingnya, dibawahnya atau diatasnya namun tidak secara langsung.

5. Variabel yang Paling Berpengaruh terhadap Keputusan Wisatawan Berkunjung

Berdasarkan hasil penelitian diketahui bahwa variabel atribute produk concept merupakan faktor dominan yang mempengaruhi keputusan wisatawan untuk berkunjungdi Kawasan Kebun Raya
Unmul Samarinda dengan koefisien sebesar 0,398, kemudian peringkat kedua diduduki variabel experimental concept dengan koefisien sebesar 0,249, dan peringkat terakhir diduduki variabel price concept dengan koefisien sebesar 0,218.

Attribute produk concept merupakan faktor dominan yang mempengaruhi keputusan wisatawan untuk berkunjung di Kawasan Kebun Raya Unmul Samarinda, hal ini dikarenakan produk merupakan suatu rangkaian jasa yang tidak hanya mempunyai segi-segi yang bersifat ekonomis, tetapi juga bersifat sosial, psikologis, dan alam, walaupun produk wisata itu sendiri sebagian besar dipengaruhi oleh tingkah laku ekonomi. Produk wisata merupakan sebuah pelayanan yang dapat dirasakan atau dinikmati oleh wisatawan saat berada di tempat wisata yang ditunjang oleh komponen produk wisata mulai dari atraksi, fasilitas, dan aksesibilitas setiap komponen tersebut telah dipersiapkan secara baik oleh pengelola.

Terdapat tiga unsur yang membentuk produk wisata antar lain: atraksi, fasilitas, dan aksesibilitas. Atraksi merupakan elemen-elemen yang terkandung dalam destinasi dan lingkungan didalamnya yang secara individual atau kombinasinya memegang peran penting dalam memotivasi wisatawan untuk berkunjung ke destinasi tersebut. Fasilitas merupakan elemen destinasi yang memungkinkan wisatawan tinggal di destinasi tersebut untuk menikmati atau berpartisipasi dalam atraksi yang ditawarkan. Fasilitas destinasi bisa berupa akomodasi, restoran, cafe, dan transportasi, serta pelayanan lain termasuk pelayanan informasi, dan sebagainya. Aksesibilitas merupakan mudah atau sulitnya wisatawan menjangkau destinasi yang diinginkannya. Akses berkaitan dengan infrastruktur transportasi, seperti lapangan udara atau bandara, terminal bus dan sebagainya.

\section{Kesimpulan}

Berdasarkan hasil penelitian dan pembahasan, maka dapat ditarik beberapa kesimpulan sebagai berikut. 
Ha diterima ada pengaruh antara experimental concept terhadap keputusan wisatawan untuk berkunjung. Hal ini dibuktikan dengan nilai thitung $\mathrm{t}$ hitung $>\mathrm{t}$ tabel $(3,049>1,661)$, signifikansi lebih kecil dari $0,05(0,003<0,05)$, dan koefisien regresi mempunyai nilai positif sebesar 0,264 .

Ha diterima ada pengaruh antara price concept terhadap keputusan wisatawan untuk berkunjung. Hal ini dibuktikan dengan $\mathrm{t}$ hitung $>\mathrm{t}$ tabel $(2,301>1,661)$, signifikansi lebih kecil dari $0,05(0,024<0,05)$, dan koefisien regresi mempunyai nilai positif sebesar 0,152. (Ha diterima, Ho ditolak).

Ha diterima ada pengaruh antara atribute produk concept terhadap keputusan wisatawan untuk berkunjung. Hal ini dibuktikan dengan $\mathrm{t}$ hitung $>\mathrm{t}$ tabel $(4,366>$ $1,661)$, signifikansi lebih kecil dari 0,05 $(0,000<0,05)$, dan koefisien regresi mempunyai nilai positif sebesar 0,355 . (Ha diterima, Ho ditolak).

Ha diterima ada pengaruh antara positioning yang terdiri dari experimental concept, price concept, dan atribute produk concept terhadap keputusan wisatawan untuk berkunjung. Hal ini dibuktikan dengan nilai $\mathrm{F}$ hitung $>\mathrm{F}$ tabel $(29,882>2,70)$ dengan nilai signifikansi lebih kecil dari 0,05 (0,000 < 0,05). ( Ha diterima, Ho ditolak).

Variabel atribute product concept
merupakan faktor dominan yang
mempengaruhi keputusan wisatawan untuk
berkunjung di Kawasan Kebun Raya Unmul
Samarinda dengan koefisien sebesar 0,398 ,
kemudian peringkat kedua diduduki variabel
experimental concept dengan koefisien
sebesar 0,249, dan peringkat terakhir
diduduki variabel price concept dengan
koefisien sebesar 0,218.

\section{Saran}

Berdasarkan hasil penelitian, pembahasan dan kesimpulan yang diperoleh, maka saran yang dapat diberikan ialah :

Berdasarkan dari hasil penelitian diketahui bahwa aspek price concept mendapat penilaian dari responden paling rendah, oleh karena itu Pengelola Kawasan Kebun Raya Unmul Samarinda disarankan untuk meningkatkan positioning daya tarik wisata dari segi price concept dengan cara harga yang ditetapkan sesuai dengan kualitas pelayanan yang diterima oleh pengunjung agar pengunjung merasa puas saat berkunjung ke kawasan Kebun Raya, sehingga dapat meningkatkan jumlah wisatawan yang berkunjung di Kawasan Kebun Raya Unmul Samarinda.

\section{References}

[1] Darmawan, Deni. 2013. Metode Penelitian Kuantitatif. Bandung. PT Remaja Rosdakarta

[2] Fandeli, Chafid. 1995. Dasar-Dasar Manajemen Kepariwisataan. Yogyakarta. Liberty.

[3] Hasan, Ali. 2009. Marketing. Yogyakarta. Medpress

[4] ....., Ali. 2013. Marketing dan Kasus-kasus pilihan. Yogyakarta. CAPS

[5] Kuncoro, Mudrajad. 2004. Metode Kuantitatif Teori dan Aplikasi Untuk Bisnis dan Ekonomi. Yogyakarta. AMP YKPN

[6] Musanef. 1996. Manajemen Usaha Pariwisata. Jakarta. Gunung Agung.

[7] Pendit, Nyoman S. 2002. Ilmu Pariwisata "Sebuah Pengantar Perdana". Jakarta. PT Pradnya Paramita

[8] Pitana, I Gde dan Gayatri. 2005. Sosiologi Pariwisata. Yogyakarta. Andi.

[9] ........, I Gde dan Diarta. 2009. Pengantar Ilmu Pariwisata. Yogyakarta. Andi.

[10] Sihite, Richard. 2000. Tourism Industry (Kepariwisataan). Surabaya. SIC

[11] Siregar, Syofian. 2013. Metode Penelitian Kuantitatif dan SPSS. Jakarta. Kencana Prenada.

[12] Sugiyono. 2013. Metode Penelitian Manajemen. Bandung. CV Alfabeta.

[13] . 2013. Metode Penelitian Kuantitatif, Kualitatif, Dan R\&D. Bandung. CV Alfabeta.

[14] Sudjana. 1996. Metode Statistik. Bandung. Tarsito.

[15] Sunyoto, Danang. 2011. Metode Penelitian Ekonomi. Yogyakarta. CAPS

[16] Suwantoro, Gamal. 2004. Dasar - Dasar Pariwisata. Yogyakarta. Andi 
[17] Tjiptono, Fandy. 1997. Strategi Pemasaran. Yogyakarta. Andi.

[18] Wahab, Salah Pd.D. 1997. Pemasaran Pariwisata. Jakarta. PT Pradnya Paramita.
[19] Yoeti, Oka A. 1996. Pengantar Ilmu Pariwisata. Bandung. Angkasa. 